\title{
Performance Analysis on the Chinese Open-end Stock Funds' Investment Style Convergence
}

\author{
Xin Zhao \\ School of Economics \& Management \\ Nanjing University of Science and Technology \\ Nanjing, China \\ E-mail: 1428181292@qq.com
}

Keywords: style convergence, fund performance, outlier strategy, personal ability.

\begin{abstract}
This paper quantitatively studies the relationship between investment style convergence and fund performance of open-end stock funds from the empirical point of view, and finds that: the convergence of the actual fund style is serious; in the long run convergence tends to reduce the fund performance, but to a lesser extent; if the fund managers have higher personal ability, outlier will significantly improve fund performance, on the contrary the relationship between convergence and performance is unstable; outlier strategy is effective on the premise that the fund managers have high personal ability.
\end{abstract}

\section{Introduction}

For a long time there is an interesting phenomenon in Chinese fund market.No matter what kind of investment style the fund declared at the beginning of its establishment, it often deviates in the actual operation process and leads to the convergence of the actual investment style.Dai Zhimin ${ }^{[1]}$, Zeng Xiaojie et al. ${ }^{[2]}$, Yuan Jing ${ }^{[3]}$ and Li Xuefeng ${ }^{[4]}$ all revealed the widespread existence of this phenomenon.It is worth mentioning that, Meng Qingbin et al. $^{[5]}$ from the perspective of holding stocks constructed an indicator to measure the behavior of huddling around some stocks in the process of selecting stock, found that in order to achieve a conservative investment style fund managers with medium ability will configure stocks with low beta and stocks which most funds huddle around,to a certain extent their research also verified the phenomenon of style convergence.The deviation from the agreed nominal investment style will weaken the style's informative function and exacerbate the information asymmetry between investors and funds. Therefore,we must pay attention to the relationship between style convergence and performance.Zhang Zongyi et al. ${ }^{[6]}$ used a three-factor model to examine the style of 51 open-end funds during the study period and found that the fund's style are very similar but can still obtain excess returns.On the basis of adding the TM model's quadratic term, Bai Qinxian ${ }^{[7]}$ extended the three-factor model to test the overall performance of 32 actively managed open-end equity funds and found that for these funds that claimed to have different investment styles the actual investment style converged, and sub-period regression results show that the funds will follow the market trend and change their style, but still do not exceed market performance.Ye Li et al. ${ }^{[8]}$ established the style identification of the 15 selected sample funds by constructing a new fund style evaluation index, and found that there was a convergence of style and no obvious difference in performance.

In this paper, we choose open-end stock funds as the research sample.Based on the identification of actual investment style, we design an index to quantify the degree of style convergence, and discuss the relationship between style convergence and fund performance in combination with the extended three-factor model.By quantitatively examining the influence of style convergence on fund performance from the empirical point of view, it is helpful to optimize individual investors' choice and consummate the institutional investors' investment strategy, and at the same time it can provide useful reference for improving the regulation of funds' investment behavior. 
The second part is sample selection and investment style identification; the third part is the index design and model setting; the fourth part is empirical analysis; the fifth part is the summary.

\section{Sample selection and investment style identification}

This paper selects open-end equity funds as a sample to study the relationship between style convergence and fund performance. The sample selection criteria are as follows:

(1) Conventional funds that are still in the market as of 2012;

(2) The nature of the fund is open-end. Investment categories are classified as capital preservation, hybrid and equity funds according to the Morningstar classification.

(3) The fund was established before 2007.

In order to include the complete stock market cycle as much as possible,the sample period is January 5, 2007 to December 16, 2011.Furthermore, 162 sample funds' weekly data for 255 weeks is collected and adjusted according to dividends reinvestment day.Meanwhile, the one-year fixed deposit interest rate is applied to the risk-free rate and adjusted to weekly data.In order to identify the style, this paper also need to select the appropriate style index.Among them, the market index, large-cap index, small-cap index, growth index, value index, government bond index use CITIC A shares KLCI (816999), CITIC Market Index (816100), CITIC Small Cap Index (816400), CITIC Growth Index (816210), CITIC Value Index (815220), CITIC S \& P Bond Index (816020) respectively, the data using the weekly returns.The above data are derived from the Resset database.

In style identification method, the Gruber four-factor model can eliminate some multicollinearity through horizontal difference processing, and also has the advantages of simple data collection, average style over a period of time, and simple statistics. Therefore, it is a more suitable identification method.This paper selects Gruber four-factor model to identify the actual style of the sample funds.Gruber ${ }^{[9]}$ added a bond factor to analyze the fund's investment style, taking into account the market, size and value-growth factors. The specific model is as follows:

$$
R_{i}-R_{f}=\alpha_{i}+\beta_{1}\left(R_{m}-R_{f}\right)+\beta_{2}\left(R_{s}-R_{1}\right)+\beta_{3}\left(R_{g}-R_{v}\right)+\beta_{4}\left(R_{B}-R_{f}\right)+e_{i}
$$

$R_{i}$ and $R_{f}$ are the return of fund $i$ and the risk-free interest rate respectively. $R_{m}, R_{s}, R_{l}, R_{g}, R_{v}$ and $\mathrm{R}_{\mathrm{B}}$ are the returns of market index, small-cap index, large-cap index, growth style index, value style index and government bond index respectively.If regression coefficients $\beta_{j}(j=2,3)$ were significantly positive, it means the fund has a small-cap and growth style.If significantly negative, it means the fund has the large-cap and value style.If not significant, it means the fund has the middle-cap and balance style.In order to get more information about the change of fund style, this paper adopts the period rolling method. We take 24 weeks as a period and 8 weeks as the rolling week, and obtain the fund style information for 31 period.Figure 1 shows the time rolling method.Table 1 shows the frequency of each mainstream investment style. The first letter S, M, L, respectively, represent the small-cap style, the middle-cap style, the large-cap style. The second letter G, B, V, respectively, represent the growth style, the balance style, the value style.As can be seen from Table 1, the actual investment style of the fund converges seriously. The frequency of the mainstream style is at a minimum about $40 \%$ and the highest is about $90 \%$. The majority is middle-cap style and balance style, followed by large-cap style and balance style.

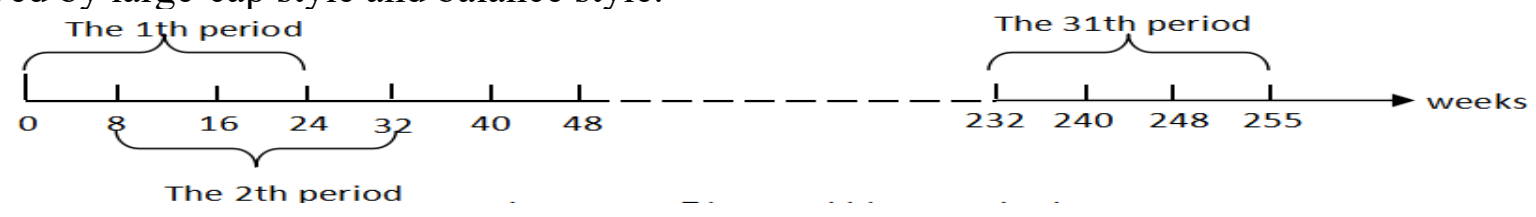

Fig. 1. Time rolling method . 
Table 1. frequency statistic on fund's mainstream style .

\begin{tabular}{llllllllllll}
\hline Period & 1th & 2th & 3th & 4th & 5th & 6th & 7th & 8th & 9th & 10th & 11th \\
\hline Mainstream & MB & LB & LB & LB & LB & MB & MB & MB & MB & MB & MB \\
\hline Frequency & 0.40 & 0.44 & 0.47 & 0.49 & 0.54 & 0.95 & 0.80 & 0.88 & 0.73 & 0.83 & 0.85 \\
\hline Period & 12th & 13th & 14th & 15th & 16th & 17th & 18th & 19th & 20th & 21th & 22th \\
\hline Mainstream & MB & MB & MB & LB & MB & MB & MB & MB & MB & MG & MG \\
\hline Frequency & $\mathbf{0 . 6 3}$ & $\mathbf{0 . 7 2}$ & $\mathbf{0 . 4 0}$ & $\mathbf{0 . 4 9}$ & $\mathbf{0 . 8 1}$ & $\mathbf{0 . 7 5}$ & $\mathbf{0 . 9 0}$ & $\mathbf{0 . 4 9}$ & $\mathbf{0 . 6 2}$ & $\mathbf{0 . 5 4}$ & $\mathbf{0 . 5 4}$ \\
\hline Period & 23th & 24th & 25th & 26th & 27th & 28th & 29th & 30th & 31th & \\
\hline Mainstream & MB & MB & MB & MB & MB & MB & MB & MB & LB & \\
\hline Frequency & $\mathbf{0 . 6 0}$ & $\mathbf{0 . 9 0}$ & $\mathbf{0 . 7 2}$ & $\mathbf{0 . 8 3}$ & $\mathbf{0 . 6 9}$ & $\mathbf{0 . 9 3}$ & $\mathbf{0 . 5 7}$ & $\mathbf{0 . 4 5}$ & $\mathbf{0 . 3 6}$ & \\
\hline
\end{tabular}

\section{Indicator design and model setting}

This paper defines convergence as the overall average style similarity between each fund and the other funds.We draws on the Morningstar style box method to create a two-dimensional coordinate system, in which the vertical axis represents the size dimension, the horizontal axis represents the growth-value dimension.For value style, balance style and growth style, the abscissa values are 0,1,2.For small-cap style,middle-cap style and large-cap style, the ordinate values are 0,1,2.The closer the fund style is to the small-cap style and value style, the closer the style coordinate is to the origin, as shown in Figure 2. In order to increase the degree of change in variables, the period rolling method and panel data are adopted.We define the outlier as the opposite of convergence. The greater the degree of outlier, the smaller the degree of convergence of the fund is.Let $\mathrm{L}_{\mathrm{i}}$ and $\mathrm{Q}_{\mathrm{i}}$ denote the outlier degree and the convergence degree of fund i respectively, $\mathrm{D}_{\mathrm{j}}$ represents the style coordinate distance between fund $i$ and other funds, then the formula of $\mathrm{Li}_{i}$ and $\mathrm{Q}_{i}$ is:

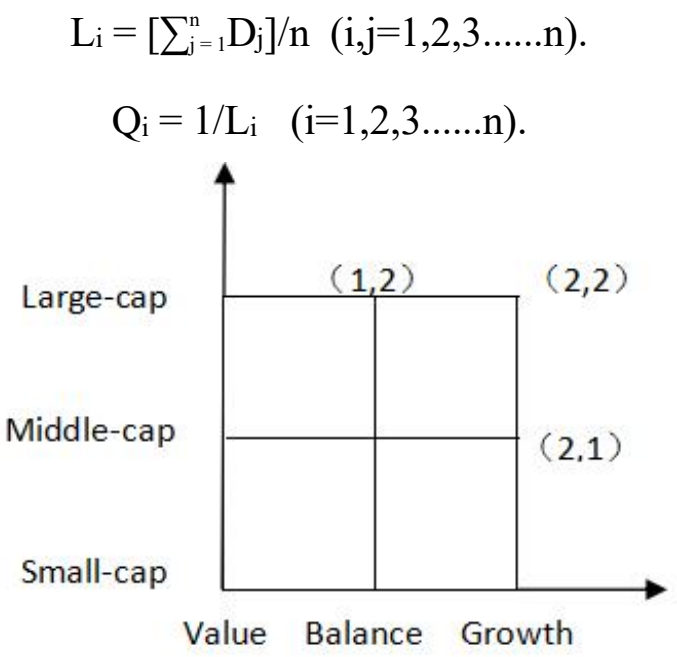

Fig. 2. Style coordinate system .

By adding the convergence factor to the three-factor model, we set up the following model:

$$
Y_{i, t}=\alpha_{i, t}+\beta_{1, i, t} X_{1, i, t}+\beta_{2, i, t} X_{2, i, t}+\beta_{3, i, t} X_{3, i, t}+\beta_{4, i, t} L_{i, t}+e_{i, t} .
$$

$Y_{i, t}=R_{i, t}-R_{f}$, is the excess return of fund $i$ in period $t, X_{1, i, t}=R_{m}-R_{f}$, is the market factor, $X_{2, i, t}=$ $R_{s}-R_{b}$, is the market capitalization factor, $X_{3, i, t}=R_{h}-R_{l}$, is the book-to-market ratio factor, and $L_{i, t}$ and $\mathrm{e}_{\mathrm{i}, \mathrm{t}}$ are the fund's outliers and random errors respectively.

Because of the existence of unit root processes for some variables, we need to take a first-order difference for all variables. At the same time, the Hausman test finds that it is more appropriate to set the model as a random effect. Due to space limitations, the relevant reports are omitted. The model is changed to:

$$
\mathrm{D}\left(\mathrm{Y}_{\mathrm{i}, \mathrm{t}}\right)=\alpha_{\mathrm{i}, \mathrm{t}}+\beta_{1, \mathrm{i}, \mathrm{t}} \mathrm{D}\left(\mathrm{X}_{1, \mathrm{i}, \mathrm{t}}\right)+\beta_{2, \mathrm{i}, \mathrm{t}} \mathrm{D}\left(\mathrm{X}_{2, \mathrm{i}, \mathrm{t}}\right)+\beta_{3, \mathrm{i}, \mathrm{t}} \mathrm{D}\left(\mathrm{X}_{3, \mathrm{i}, \mathrm{t}}\right)+\beta_{4, \mathrm{i}, \mathrm{t}} \mathrm{D}\left(\mathrm{L}_{\mathrm{i}, \mathrm{t}}\right)+\mathrm{e}_{\mathrm{i}}
$$


Considering that the fund may hold a certain characteristic asset for a period of time, the degree of convergence in the past may also have an impact on the current returns. Therefore, we establish the following four regression models, in which the convergence variables use the current and lagged 1-3 period data, the four models are as follows:

$$
\begin{aligned}
& \mathrm{D}\left(\mathrm{Y}_{\mathrm{i}, \mathrm{t}}\right)=\alpha_{\mathrm{i}, \mathrm{t}}+\beta_{1, \mathrm{i}, \mathrm{D}} \mathrm{D}\left(\mathrm{X}_{1, \mathrm{i}, \mathrm{t}}\right)+\beta_{2, \mathrm{i}, \mathrm{D}} \mathrm{D}\left(\mathrm{X}_{2, \mathrm{i}, \mathrm{t}}\right)+\beta_{3, \mathrm{i}, \mathrm{t}} \mathrm{D}\left(\mathrm{X}_{3, \mathrm{i}, \mathrm{t}}\right)+\beta_{4, \mathrm{i}, \mathrm{t}} \mathrm{D}_{\mathrm{t}}\left(\mathrm{L}_{\mathrm{i}, \mathrm{t}}\right)+\mathrm{e}_{\mathrm{i}, \mathrm{t}} . \\
& \mathrm{D}\left(\mathrm{Y}_{\mathrm{i}, \mathrm{t}}\right)=\alpha_{\mathrm{i}, \mathrm{t}}+\beta_{1, \mathrm{i}, \mathrm{D}} \mathrm{D}\left(\mathrm{X}_{1, \mathrm{i}, \mathrm{t}}\right)+\beta_{2, \mathrm{i}, \mathrm{t}} \mathrm{D}\left(\mathrm{X}_{2, \mathrm{i}, \mathrm{t}}\right)+\beta_{3, \mathrm{i}, \mathrm{t}} \mathrm{D}\left(\mathrm{X}_{3, \mathrm{i}, \mathrm{t}}\right)+\beta_{4, \mathrm{i}, \mathrm{t}} \mathrm{D}_{\mathrm{t}-1}\left(\mathrm{~L}_{\mathrm{i}, \mathrm{t}}\right)+\mathrm{e}_{\mathrm{i}, \mathrm{t}} . \\
& \mathrm{D}\left(\mathrm{Y}_{\mathrm{i}, \mathrm{t}}\right)=\alpha_{\mathrm{i}, \mathrm{t}}+\beta_{1, \mathrm{i}, \mathrm{D}} \mathrm{D}\left(\mathrm{X}_{1, \mathrm{i}, \mathrm{t}}\right)+\beta_{2, \mathrm{i}, \mathrm{t}} \mathrm{D}\left(\mathrm{X}_{2, \mathrm{i}, \mathrm{t}}\right)+\beta_{3, \mathrm{i}, \mathrm{t}} \mathrm{D}\left(\mathrm{X}_{3, \mathrm{i}, \mathrm{t}}\right)+\beta_{4, \mathrm{i}, \mathrm{t}} \mathrm{D}_{\mathrm{t}-2}\left(\mathrm{~L}_{\mathrm{i}, \mathrm{t}}\right)+\mathrm{e}_{\mathrm{i}, \mathrm{t}} . \\
& \mathrm{D}\left(\mathrm{Y}_{\mathrm{i}, \mathrm{t}}\right)=\alpha_{\mathrm{i}, \mathrm{t}}+\beta_{1, \mathrm{i}, \mathrm{D}} \mathrm{D}\left(\mathrm{X}_{1, \mathrm{i}, \mathrm{t}}\right)+\beta_{2, \mathrm{i}, \mathrm{t}} \mathrm{D}\left(\mathrm{X}_{2, \mathrm{i}, \mathrm{t}}\right)+\beta_{3, \mathrm{i}, \mathrm{t}} \mathrm{D}\left(\mathrm{X}_{3, \mathrm{i}, \mathrm{t}}\right)+\beta_{4, \mathrm{i}, \mathrm{t}} \mathrm{D}_{\mathrm{t}-3}\left(\mathrm{~L}_{\mathrm{i}, \mathrm{t}}\right)+\mathrm{e}_{\mathrm{i}, \mathrm{t}} .
\end{aligned}
$$

\section{Empirical analysis}

We use the fund managers' ability to explore the structural effect.Drawing on Jensen's ${ }^{[10]}$ concept of evaluating portfolio performance, this paper establishes the Fama-French three-factor model. After excluding the contribution of the market premium factor $\mathrm{X}_{1, \mathrm{i}, \mathrm{t}}$, the market capitalization factor $\mathrm{X}_{2, \mathrm{i}, \mathrm{t}}$ and the book-to-market ratio factor $\mathrm{X}_{3, \mathrm{i}, \mathrm{t}}$ to the fund's excess returns, the remaining intercept item $\alpha$ is considered as a manifestation of individual managers' ability.If the intercept term is positive, then the fund manager has a higher personal ability. If the intercept term is negative, it indicates that the fund manager does not have a high personal ability.After obtaining the $\alpha$ values of the funds for each period, we calculate the mean and median of the funds' $\alpha$ values for each period. Finally,two subsamples are chosen. One is a sample with positive median and mean, and the other is a sample with negative median and mean.The structural effect regression results are shown in Table 2 and Table 3.The regression model used to find the $\alpha$ values is as follows:

\begin{tabular}{|c|c|c|c|c|}
\hline Variables & Model1 & Model2 & Model3 & Model4 \\
\hline Constant & $\begin{array}{c}-0.0035 \\
\left(-2.25^{* *}\right)\end{array}$ & $\begin{array}{c}-0.0038 \\
(-2.49 * *)\end{array}$ & $\begin{array}{c}-0.0058 \\
\left(-3.75^{* *}\right)\end{array}$ & $\begin{array}{c}-0.0026 \\
(-1.64)\end{array}$ \\
\hline $\mathrm{D}(\mathrm{X} 1)$ & $\begin{array}{c}0.7167 \\
\left(108.58^{* *}\right)\end{array}$ & $\begin{array}{c}0.7382 \\
(101.09 * *)\end{array}$ & $\begin{array}{c}0.7341 \\
\left(111.57^{* *}\right)\end{array}$ & $\begin{array}{c}0.7138 \\
(99.16 * *)\end{array}$ \\
\hline $\mathrm{D}(\mathrm{X} 2)$ & $\begin{array}{c}-0.2197 \\
\left(-11.64^{* *}\right)\end{array}$ & $\begin{array}{c}-0.1951 \\
(-9.83 * *)\end{array}$ & $\begin{array}{c}-0.1577 \\
(-7.61 * *)\end{array}$ & $\begin{array}{c}-0.1141 \\
(-4.97 * *)\end{array}$ \\
\hline $\mathrm{D}(\mathrm{X3})$ & $\begin{array}{c}-0.2654 \\
(-8.63 * *)\end{array}$ & $\begin{array}{c}-0.1976 \\
\left(-6.21^{* *}\right)\end{array}$ & $\begin{array}{c}-0.1521 \\
(-4.68 * *)\end{array}$ & $\begin{array}{c}-0.1448 \\
\left(-4.37^{* *}\right)\end{array}$ \\
\hline $\mathrm{D}(\mathrm{L})$ & $\begin{array}{c}0.2691 \\
(7.32 * *)\end{array}$ & $\begin{array}{c}0.0912 \\
\left(2.17^{* *}\right)\end{array}$ & $\begin{array}{c}0.1164 \\
(3.16 * *)\end{array}$ & $\begin{array}{c}-0.2041 \\
(-5.44 * *)\end{array}$ \\
\hline $\mathbf{R}^{2}$ & 0.8921 & 0.8965 & 0.9015 & 0.8941 \\
\hline Adjusted $\mathbf{R}^{2}$ & 0.8919 & 0.8963 & 0.9012 & 0.8938 \\
\hline
\end{tabular}

$$
Y_{i, t}=\alpha_{i, t}+\beta_{1, i, t} X_{1, i, t}+\beta_{2, i, t} X_{2, i, t}+\beta_{3, i, t} X_{3, i, t}+e_{i, t} .
$$

Table 2. Subsample regression results(ALPHA $>0$ ).

Note: The convergence variables use the current and lagged 1-3 period data in model 1-4 respectively.** means that the variables are significant at $10 \%$ and $5 \%$ respectively.

As can be seen from Table 2, variables for all four cases are significant for the sample with the $\alpha$ greater than zero.Overall, if fund managers have higher personal ability, they can obtain outstanding returns in the current period, laggged one period and laggged two period without following the mainstream. This may be due to the correct stock selection and appropriate timing as well as early 
entry to obtain a lower price.However, it is worth noting that if the fund does not follow the mainstream in lagged three period, it will lose higher returns. The possible explanation is that fund managers are overconfident and hold assets for too long, and they do not withdraw from the market in time to lock the proceeds when the market shifts hot spot.It also means that the market must be respected in all circumstances.On average, fund managers with higher personal ability get better returns by adopting outlier strategy.

Table 3. Subsample regression results $(\mathrm{ALPHA}<0)$.

\begin{tabular}{|c|c|c|c|c|}
\hline Variables & Model1 & Model2 & Model3 & Model4 \\
\hline $\mathbf{C}$ & $\begin{array}{l}-0.0023 \\
(-1.82 *)\end{array}$ & $\begin{array}{c}-0.0033 \\
(-2.62 * *)\end{array}$ & $\begin{array}{c}-0.0050 \\
(-3.91 * *)\end{array}$ & $\begin{array}{c}-0.0040 \\
(-3.11 * *)\end{array}$ \\
\hline D(X1) & $\begin{array}{c}0.6889 \\
(121.18 * *)\end{array}$ & $\begin{array}{c}0.6935 \\
(126.92 * *)\end{array}$ & $\begin{array}{c}0.6933 \\
\left(126.78^{* *}\right)\end{array}$ & $\begin{array}{c}0.6830 \\
(118.38 * *)\end{array}$ \\
\hline $\mathrm{D}(\mathrm{X} 2)$ & $\begin{array}{c}-0.2641 \\
(-16.49 * *)\end{array}$ & $\begin{array}{c}-0.2362 \\
(-15.03 * *)\end{array}$ & $\begin{array}{c}-0.1928 \\
\left(-11.05^{* *}\right)\end{array}$ & $\begin{array}{c}-0.1550 \\
\left(-8.25^{* *}\right)\end{array}$ \\
\hline $\mathrm{D}(\mathrm{X3})$ & $\begin{array}{c}-0.2838 \\
(-10.84 * *)\end{array}$ & $\begin{array}{c}-0.2516 \\
(-9.68 * *)\end{array}$ & $\begin{array}{c}-0.2081 \\
\left(-7.76^{* *}\right)\end{array}$ & $\begin{array}{c}-0.1697 \\
(-6.13 * *)\end{array}$ \\
\hline $\mathrm{D}(\mathrm{L})$ & $\begin{array}{c}-0.0057 \\
(-1.53)\end{array}$ & $\begin{array}{c}0.0082 \\
\left(2.47^{* *}\right)\end{array}$ & $\begin{array}{c}-0.0050 \\
(-1.44)\end{array}$ & $\begin{array}{c}0.0117 \\
(3.35 * *)\end{array}$ \\
\hline $\mathbf{R}^{2}$ & 0.8693 & 0.8752 & 0.8794 & 0.8709 \\
\hline Adjusted $\mathbf{R}^{2}$ & 0.8691 & 0.8750 & 0.8792 & 0.8707 \\
\hline
\end{tabular}

Note: The convergence variables use the current and lagged 1-3 period data in model 1-4 respectively.* means that the variables are significant at $10 \%,{ }^{* *}$ means that the variables are significant at $10 \%$ and $5 \%$ respectively.

It can be seen from Table 3 that for the sample with the $\alpha$ less than zero, the index of outlier is not significant in both current and lagged two period, and the remaining variables are significant.In general, if the manager's personal ability is not high, the relationship between convergence and performance is not obvious.In some cases, there is a slight gain without following the mainstream, but it may also do not have an impact on returns whether they follow the mainstream or not.The possible explanation is that with or without maintaining the mainstream style, the key is the fund managers are expert in stock selection and market timing. Even if the corresponding assets are acquired at a lower price, the lack of ability will make this advantage weakened. On the contrary, while acquiring assets at higher price adds cost, higher ability will make up for that.Therefore, in order to gain more than market returns, outlier strategy is effective on the premise that fund managers have a higher personal ability.On average, if fund managers are not personally competent, there is an unstable correlation between convergence and performance.

\section{Summary}

Based on the actual style identification and convergence quantification, this paper conducts an empirical analysis of the relationship between style convergence and fund performance on structure effect, and draws the following conclusions:

(1) Fund generally deviate from the nominal investment style, and most of the actual investment style is a "middle-cap and balance" style.

(2) In general, although it will lose the current returns, it is a more reasonable strategy in the long run to avoid convergence.

(3) If the fund manager has a higher personal ability, non-convergence strategy will bring significant benefits, but there may be overconfidence. 
(4) If the fund manager's personal ability is not strong, the convergence of investment style has a limited impact on returns, but outlier will receive weak returns.

(5) Outlier strategy must be based on the high ability of stock selection and market timing, the weak individual managers will weaken the effect of outlier strategy.

\section{References}

[1] Z.M.Dai, On the Consistence of the Investment Style of Open-ended Mutual Fund in China, Journal of Zhejiang University, vol.33, pp.33-39,2003.

[2] X.J.Zeng, S.Huang, G.Q.Chu, An empirical study on fund investment style and fund classification, Journal of Financial Research, pp.66-78,2003.

[3] J.Yuan, The factor analysis on convergence of Chinese open-fund' investment style, Reform of Economic System, pp.126-130, 2005.

[4] X.F.Li, H.Xu, R.X.Li, Fund's Investment Style Consistency and Its Influence on Fund Performance, Finance \& Trade Research, pp.89-97, 2010.

[5] B.Q.Meng, W.X.Wu, S.Y.Yu, Fund managers' career concern and their investment style, Economic Research Journal, pp.115-130, 2015.

[6] Z.Y.Zhang, L.H.Xiang, Empirical Research on Open-ended Equity Fund Performance Based on Style Adjustments, Technology Economics, vol.29, pp.78-82, 2010.

[7] Q.X.Bai, X.Y.Wang, Y.Y.Qu, Overall Performance Estimation of Fund Companies and Analysis of Investment Styles, Contemporary Finance \& Economics, vol.37, pp.43-55, 2013.

[8] L.Ye, W.Liu, Study of Evaluation on Investing Style of Open Funds in China, Modern Finance \& Economics, vol.26, pp.24-28,2006.

[9] Gruber Martin J,Another Puzzle:the Growth in Activity Managed Mutual Funds, The Journal of Finance, vol.51, pp.783-810,1996.

[10]Michael C.Jensen, The Performance of Mutual Funds in Period 1945-1964, Journal of Finance, vol.23, pp.389-416,1968. 